$$
\begin{aligned}
& \text { CONF-9606116--74 } \\
& \text { UCRL-JC-123079 }
\end{aligned}
$$

\title{
Developing Inertial Fusion Energy - Where Do We Go From Here?
}

B. G. Logan

$$
\begin{aligned}
& \text { REGENED } \\
& \text { AUG } 161996 \\
& \text { OSTI }
\end{aligned}
$$

This paper was prepared for submittal to the American Nuclear Society 12th Topical Meeting on the Technology of Fusion Energy

Reno, Nevada

June 16-20, 1996

June 11, 1996

This is a preprint of a paper intended for publication in a journal or proceedings. Since changes may be made before publication, this preprint is made available with the understanding that it will not be cited or reproduced without the permission of the author.

$$
\text { DISTRIBUTION OF THIS DOCUMENT IS UNL HTIED }
$$




\section{DISCI.AIMER}

This document was prepared as an account of work sponsored by an agency of the United States Government. Neither the United States Government nor the University of California nor any of their employees, makes any warranty, express or implied, or assumes any legal liability or responsibility for the accuracy, completeness, or usefulness of any information, apparatus, product, or process disclosed, or represents that its use would not infringe privately owned rights. Reference herein to any specific commercial product, process, or service by trade name, trademark, manufacturer, or otherwise, does not necessarily constitute or imply its endorsement, recommendation, or favoring by the United States Government or the University of California. The views and opinions of authors expressed herein do not necessarily state or reflect those of the United States Government or the University of California, and shall not be used for advertising or product endorsement purposes. 


\section{DISCLATMER}

Portions of this document may be illegible in electronic image products. Images are produced from the best available original document. 


\title{
DEVELOPING INERTIAL FUSION ENERGY - WHERE DO WE GO FROM HERE?
}

\author{
Wayne R. Meier and B. Grant Logan \\ Lawrence Livermore National Laboratory \\ P.O. Box 808, L-481 \\ Livermore, CA 94583 \\ (510) $422-8536$
}

\begin{abstract}
Development of inertial fusion energy (IFE) will require continued research and development in target physics, driver technology, target production and delivery systems, and chamber technologies. It will also require the integration of these technologies in tests and engineering demonstrations of increasing capability and complexity. The development needs in each of these areas are discussed. We show how IFE development will leverage off of the Department of Energy (DOE) Defense Programs funded inertial confinement fusion (ICF) work.
\end{abstract}

\section{INTRODUCTION}

In U.S. Government Fiscal Year 1996, approximately $\$ 240 \mathrm{M}$ will be spent by the DOE Defense Programs (DP) on ICF. The near term goal of DP's ICF program is to complete the construction of the National Ignition Facility (NIF) and demonstrate ignition in an ICF capsule that will yield $\sim 20 \mathrm{MJ}$ in a single shot. ${ }^{1.2}$ The primary mission of the NIF is science based stockpile stewardship.

Another potential future application of ICF is the production of electric power. DOE's Office of Fusion Energy in Energy Research (ER) is currently spending $\sim \$ 8 \mathrm{M} / \mathrm{yr}$ on IFE, primary in support of heavy ion driver R\&D at Lawrence Berkeley National Laboratory (LBNL) and Lawrence Livermore National Laboratory (LLNL). For the past several years, we have been engaged in long term planning studies to identify the steps required to develop IFE. ${ }^{3.4}$ The plans are periodically updated to reflect changing budget constraints and technology developments. Although the DP mission beyond NIF is not clearly defined, in our planning we have assumed that DP will pursue high yield, single shot (or very low reprate) ICF applications and will develop the driver, target and chamber technologies needed for these applications. While IFE can leverage off the technology developed for ICF, there are many IFE-specific development needs that must be addressed by ER if IFE is to be advanced as an energy option. IFE-specific development needs include: high gain targets, efficient, high rep-rate drivers, high reprate, low cost target production, injection and tracking, and high rep-rate, high-fluence chambers. For energy applications, reliable, safe, and economical operation of the integrated system is required.

As indicated in Fig. 1, we have divided the R\&D needs for IFE into five categories: Target Physics, Driver Technology, Target Systems (production and injection), Chamber Technologies, and Integrated Systems (e.g., the Post NIF Facility (PNF), Pilot Plant, and Demo). The bullets listed under each item indicate the primary objectives or issues addressed in each of these areas. These are discussed in more detail in the sections below.

\section{TARGET PHYSICS}

The key issue in the area of target physics is: Can ICF achieve high enough gain to make IFE practical? Quantification of how high is high enough primarily depends on the efficiency of the driver used to ignite the target, with typical gains of 50 to 150 being appropriate for IFE.

\section{A. Target Physics Strategy}

Uncertainties in target performance and eventual IFE implementation require continued development of both direct- and indirect-drive options. The implementation of direct- and indirect-drive in an IFE power plant also has many uncertainties that will effect the decision even if both approaches had identical gain versus energy scaling (gain curve). Differences in required irradiation geometry impact the chamber design (e.g., use of a liquid wall chamber such as HYLIFE-II is not well suited to directdrive), and the survivability of targets during injection may require different approaches (e.g., direct-drive capsules will require a protective sabot, while indirect drive capsules should be adequately protected by the hohlraum). Thus, based on these uncertainties in target 


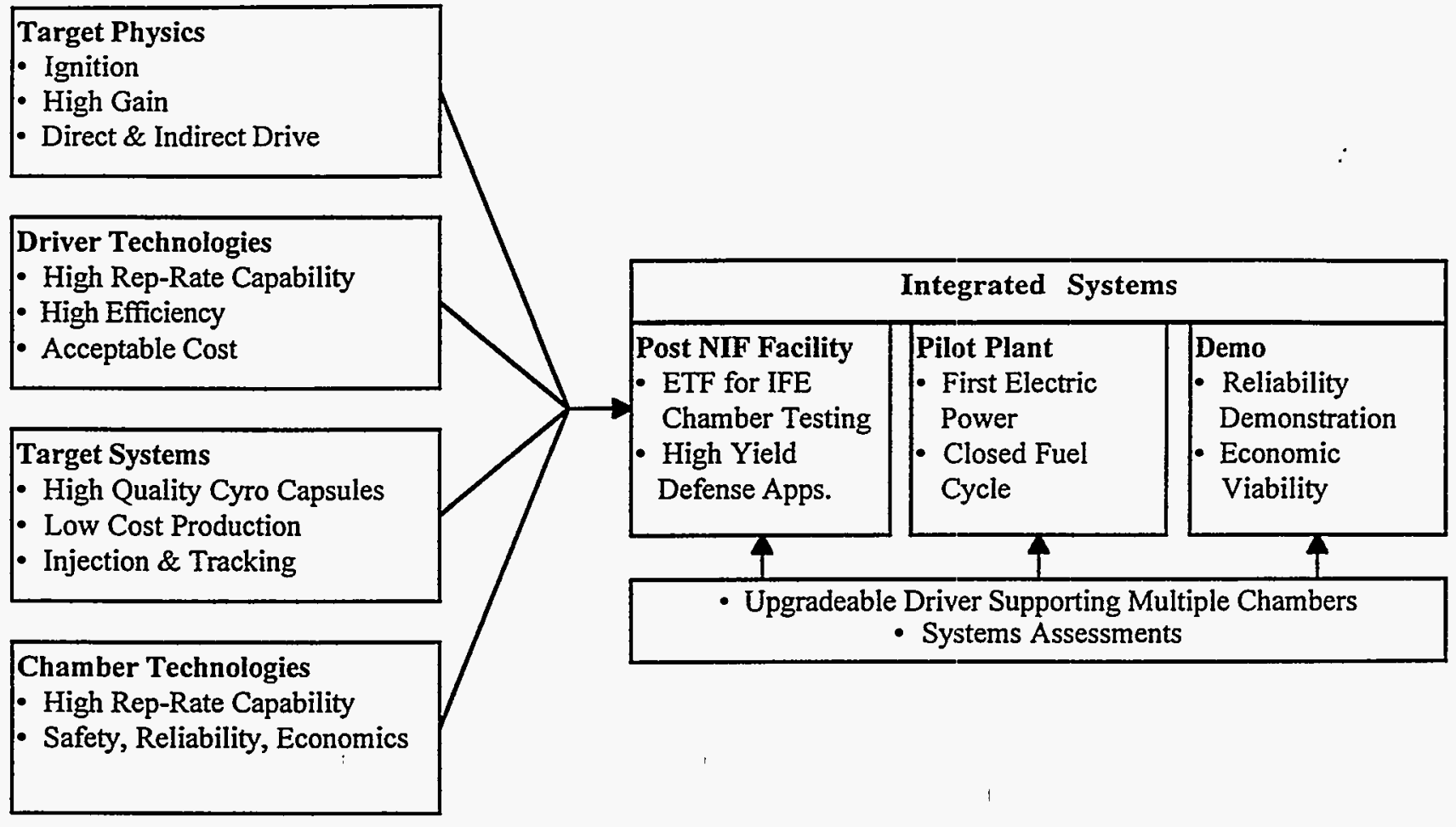

Fig. 1. Development of IFE requires R\&D in Target Physics, Driver Technologies, Target Systems, and Chamber Technologies. These technologies are integrate first in the Post NIF Facility (which includes an Engineering Test Facility for IFE and a High Yield Facility for defense applications using a single driver), followed by a pilot plant for the first demonstration of net power, and a demonstration power plant to demonstrate reliability and economics viability: It may be possible to use a single, upgradeable driver for all three phases.

performance and the eventual implementation for IFE, development of both direct- and indirect-drive approaches to ICF is assumed to continue through testing on NIF.

\section{B. Major Elements of Target Physics R\&D}

Over the next $10+$ years, ICF target physics will be the largest part of the DOE's activity related to development of IFE. Current and planned activities are listed in Table I. Research on indirect-drive targets is primarily being conducted at LLNL on the Nova laser. Direct-drive R\&D is being carried out at the University of Rochester Lab for Laser Energetic (LLE) using Omega (a glass laser) and at the Naval Research Lab using Nike (a $\mathrm{KrF}$ gas laser). ${ }^{5,6}$ By the year 2001, Omega is expected to be providing information on the performance of directdrive, cryogenic targets. Omega results that extrapolate to targets gains $>100$ will provide confidence in continued pursuit of direct-drive for IFE. NIF construction will be completed in 2002 and ignition achieved in 2005. NIF will test both direct- and indirect-drive targets, hopefully providing a clear picture of the potential performance of these two approaches.

TABLE I. Target Physics Activities.

\begin{tabular}{|l|l|l|}
\hline R\&D Element & Target Type & Status \\
\hline Nova & Indirect & Operating \\
\hline Omega & Direct & Operating \\
\hline Nike & Direct & Operating \\
\hline NIF & Direct / Indirect & 2002 Start \\
\hline IFE Target R\&D & Direct / Indirect & Ongoing \\
\hline
\end{tabular}

In addition to these DP activities, Lasnex calculations are being carried out at LLNL to develop and validate target designs for heavy ion (HI) fusion. Fullyqualified 2- and 3-D integrated designs for high gain direct- and indirect-drive IFE targets using more sophisticated tools, such as ICF3D with improved hydro modeling, are needed. This work is being conducted with joint $D P$ and $E R$ funding. 
Proposed IFE-specific target physics R\&D includes experiments on Nova, Omega, and NIF once it is operational. Planned experiments include simulation of ion-driven targets. These activities will focus on targets needed to meet IFE requirements of high gain, high reprate and low cost. As a results, studies and experiments will address the effects on target performance (i.e., gain) of using materials suitable for mass production and compatible with chamber operation.

\section{DRIVER TECHNOLOGY}

The key issue is: Can a driver with appropriate beam transport, target coupling, rep-rate, efficiency and cost characteristics be developed for IFE?

\section{A. Driver Technology Development Strategy}

The driver technology development plan is based on the assumptions that 1) the next larger driver after NIF will be used for both defense and energy applications, and 2) candidate driver options for both direct- and indirectdrive IFE should be preserved (in part reflecting the uncertainties in target performance). To keep development costs low, the driver technologies are developed in a modular fashion (i.e., proceeding from a small-scale beamlet, to multi-aperture beamline, to a full scale PNF driver).

\section{B. Major Elements of Driver Technology R\&D}

As indicated above, we propose continued development of driver options for both direct- and indirect-drive IFE. Several driver technologies are currently supported by DP for the high yield, post-NIF ICF capability; these include glass lasers, $\mathrm{KrF}$ lasers, and light-ion accelerators. In addition to these drivers, we propose continued development of 1) heavy-ion induction accelerators (linear and recirculating) primarily for indirectdrive (although direct-drive is still an open question) and 2) the diode pumped solid state laser (DPSSL) primarily for direct-drive, since we feel that the higher gain potential of direct-drive targets will be needed by DPSSLs with efficiencies of $10 \%$ or less.

The only driver currently funded by $E R$ is the induction accelerator, which is projected to have high enough efficiency to accommodate the somewhat lower target gains currently anticipated with indirect-drive and can operate at the high rep-rate required for IFE.? Unfortunately, Lawrence Berkeley National Lab's (LBNL) proposed Induction Linac Systems Experiments (ILSE) and Elise projects did not receive construction funding. The currently proposed activities for $\mathrm{HI}$ accelerators are listed in Table II. These include a combination of theory, experiments, technology development, and work on cost reduction.

TABLE II R\&D Activities Proposed for HI Accelerators.

- Theory, including end-to-end accelerator simulation

- Small-scale experiments (transport, combining, focusing, matching)

- High current, full scale transport

- Bending and recirculation

- Advanced ion sources

- Very high current injector

- Induction cavities, vacuum, alignment

- Ferromagnetic materials and cores

- Inexpensive insulators

- Pulsers

- Electrostatic quadrupole arrays

- Superconducting quadrupole arrays

- University and industrial collaboration

It is anticipated that in 1-2 years, the program will be in a position to propose an affordable experimental facility with significantly more capability than ILSE or Elise. The proposed near-term development path is illustrated in Fig. 2. The plan is to proceed from the theory, beam experiments, and component development activities listed in Table II to design and construction of a $1-30 \mathrm{~kJ}$ facility capable of conducting integrated research experiments (including putting a beam on target). Information learned in this facility will support design and construction of an intermediate driver facility (IDF) with a beam energy in the range of 100's of $\mathrm{kJ}$.

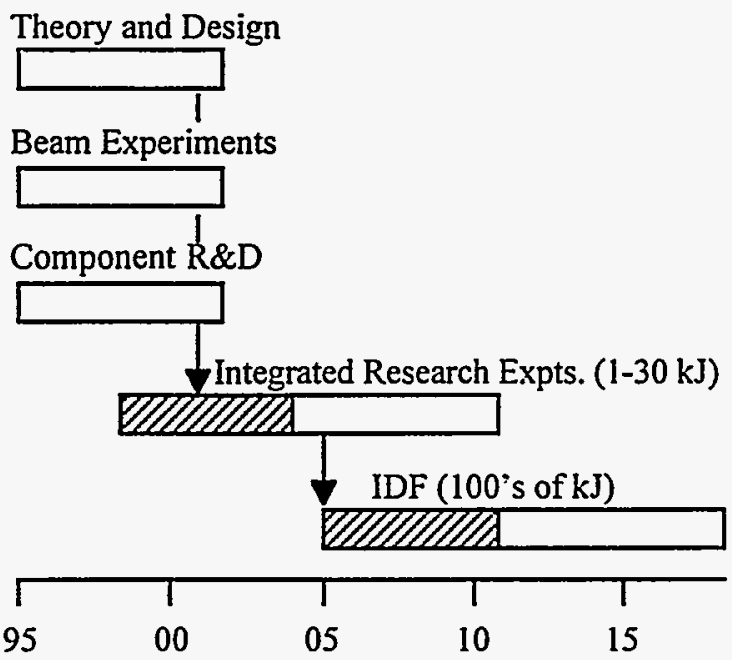

Fig. 2. Proposed development plan for $\mathrm{HI}$ accelerators. The shaded regions indicate design and construction. 
Development of the DPSSL has advanced significantly in the past several years. ${ }^{8.9}$ Continued development is needed to demonstrate scaling to larger sizes and cost reduction of the laser diodes. Small scale experiments at high rep-rate have been completed at LLNL on internal funding. A proposal to build a $100 \mathrm{~J}$, $\sim 1 \mathrm{~kW}$ laser is under consideration. Figure 3 illustrates a possible near-term development path for DPSSLs, proceeding from the $100 \mathrm{~J}$ Mercury to a $1 \mathrm{~kJ}$ Beamlet and then to a $30 \mathrm{~kJ}$ Beamline (i.e., multi-aperture laser). The $100 \mathrm{~J}$ demonstration coupled with a reduction of diode costs to $\$ 1 / \mathrm{W}$ are important near-term milestones for the DPSSL.

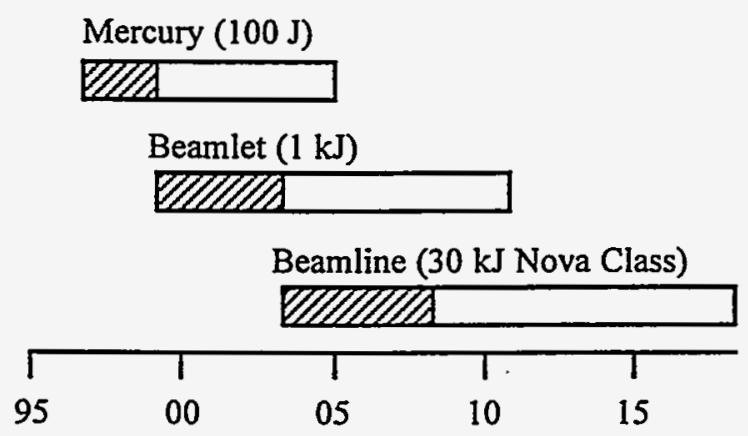

Fig. 3. Phased development activities proposed for the DPSSL. The shaded regions indicates design and construction and the open bands indicate operation.

Key IFE-specific R\&D needs include high rep-rate operation with good beam quality, component cooling, high rep-rate beam switching and transport, and final optics survivability.

If funding is available to develop the candidate drivers as discussed above, and the ICF target physics program proceeds as planned (obviously, two big if's), enough information should be available to choose a driver/target combination for IFE the shortly after ignition is achieved on NIF (i.e., after 2005). This would initiate the construction of a PNF prototype beamline. ER supported R\&D would continue on high rep-rate aspects of the PNF, while the majority of the development and construction cost are assumed to be shared DP/ER activities. The prototype beamline is constructed and operated to provide information in support of the decision to proceed with construction of the PNF, which could be as early as 2015 .

DP-funded driver technology R\&D on glass, light ions, and $\mathrm{KrF}$ would continue in support of the high yield defense applications. While both light ion and $\mathrm{KrF}$ drivers also have potential as IFE drivers, glass could only be used if the high yield facility was a defense-only facility with a low shot rate requirement (i.e., many targets per day versus many targets per second needed by IFE).

\section{TARGET SYSTEMS TECHNOLOGY}

The key issue in this area is: Can high gain, high yield targets be produced, injected, and irradiated at high rep-rate, with high reliability, and at an acceptably low cost for IFE?

\section{A. Target Systems Development Strategy}

This development category includes all the technologies needed for manufacture, storage, handling, injection and tracking of target for ICF and IFE. Target fabrication efforts must build on DP's capabilities; a separate, ER-funded program would not be cost effective. In the near term, DP and ER needs are the same development and demonstration of cryogenic targets for Omega and NIF. Feasibility tests for injection can be delayed until after the cryo target design is defined, but must be complete before construction of the PNF. In order to keep development costs low, target factory, injection and tracking technologies should be developed in a series of small, non-nuclear, build-and-test experiments.

\section{B. Major Elements of Target Systems R\&D}

The DP effort includes target fabrication for existing ICF facilities, technology R\&D in support of Omega and NIF (e.g., cryogenics) and R\&D in support of the PNF (e.g., high yield targets and possibly low rep-rate injection). Successful development of cryo targets for Omega is a key milestone ( FY-2000).

ER supported R\&D for low cost target fabrication and high rep-rate target injection and tracking is needed. Most of these activities are assumed to be delayed until development of characteristic cryogenic targets is completed. LBNL has recently initiated a contract to conduct a non-cryo of injection and tracking experiment, building on recent analytical work on target injection and tracking. ${ }^{10}$ This experiment will address concerns about the feasibility of this particular aspect of high rep-rate IFE. In order to support a decision to proceed with the energy mission of the PNF (i.e., the ETF), proof-of-principle, non-nuclear testing of fabrication, injection and tracking should be completed by about 2007 .

After choice of a driver/target combination for IFE (shortly after ignition on NIF at earliest), R\&D would 
focus on the needs for high rep-rate fabrication and injection to support the ETF and Pilot Plant.

\section{FUSION CHAMBER TECHNOLOGIES}

The key issue is: Can fusion chamber technologies capable of operating at high rep-rate and meeting environmental, safety and economic goals be developed? Fusion chamber technologies include the chamber (first wall, blanket, vacuum vessel), shielding, and tritium systems (breeding, processing, and control).

\section{A. Fusion Chamber Development Strategy}

The chamber technology development plan assumes continued synergy and cooperation between DP and ER activities in this area. For example, first wall modeling and analysis and neutron activation and safety analysis tools developed to evaluate potential IFE chamber concepts are now being used analyze the NIF chamber first wall and target building. Likewise, IFE can expect to benefit from future ICF developments. DP-funded activities will focus on high yield issues, while ERfunded activities will focus on high rep-rate issues. Emphasis should be placed on early demonstration of the feasibility of liquid wall chambers due to the high potential pay-off in reduced radiation damage, activation, and maintenance. Since the construction of a new neutron source is very uncertain, the use of existing radiation sources and radiation damage modeling to evaluate candidate materials for chambers and optics will be important. Small, non-nuclear tests of chamber concepts will build credibility and confidence for fusion testing in the ETF. One such experiment is underway at the University of California, Berkeley."

\section{B. Major Elements of Fusion Chamber R\&D}

DP-funded R\&D on target chambers is expected to continue primarily in support of high yield, single shot ICF, including first wall protection, shielding, final focusing elements (optics or magnets), etc. This activity is already in progress for the NIF target chamber. The codes and techniques being developed to support DP will be applicable to IFE (e.g., Ref. 12).

ER support is needed to fund $R \& D$ related to high rep-rate operation (chamber dynamics, first wall recovery, etc.) and high fluence radiation damage to chamber materials and focusing systems. In the near term, Nova and new ICF capabilities will be used for IFE-related experiments primarily aimed at improving predictive code capabilities. Non-nuclear, proof-of-principle testing for liquid wall chamber concepts should be completed in time to support the driver/target decision

Technology development specifically for ETF chambers begins after the target/driver decision (after 2005). More than one chamber concept will be developed to the point where high rep-rate, high-yield tests can be carried out on the ETF.

\section{INTEGRATED SYSTEMS}

Here the key questions are: Can the target, driver, and chamber technologies be integrated to demonstrate IFE power production? What are the environmental and safety, reliability, and economic characteristics of such a plant?

\section{A. Strategy for Integrated Systems}

As previously mentioned, we assume that the PNF, the next major target shooting facility beyond NIF, will be a combined DP/ER facility that uses a single driver with beam switching capability to allow it to be directed to either a high yield chamber for defense applications or to an ETF for IFE chamber testing. The driver technology will have been demonstrated in the prototype PNF beamline (see Driver Technologies section). The PNF first demonstrates high gain and high yield and tests candidate chambers at high rep-rate. We capitalize on the separability of the driver and chamber to test and prove chamber concepts at small scale and low cost. The first phase of operation supports an industry decision to proceed with a Pilot Plant to demonstration net power production. The Pilot Plant could use the PNF driver, but would require modifications and/or upgrades to the beam transport lines, target systems, and chamber. The pilot plant would also require the balance of plant equipment needed for heat removal and power conversion. This dual-use, multi-phase development strategy minimizes the driver investment required to demonstrate IFE.

\section{B. Major Elements of the Integrated Systems Areas}

Ongoing systems assessment efforts support both defense and energy applications and are funded by both $D P$ and ER. Assessments include E\&S, economics, reliability, maintainability, etc. and provide input to the various program decisions.

The first element under Integrated Systems is the PNF with dual-use capability. Sharing a driver is the most cost effective approach to meeting both defense and energy needs, but from the stand point of developing IFE, 
the sequence of events is the same whether or not the PNF is a combined DP/ER facility or a stand alone IFE development facility. The first phase is a DP facility for high yield, single shot (or very low rep-rate) target experiments. If the driver is a heavy ion accelerator, it with be the first demonstration of ignition and gain with an ion driver. In either case (laser or $\mathrm{HI}$ ) it will be the first demonstration of high gain with an efficient high reprate driver. The next step needed for IFE is the demonstration of high rep-rate in subscale test chambers. These would typically be short duration (burst mode) experiments to verify predicted chamber dynamics (chamber clearing required for beam propagation, etc.). A target factory will be needed to support this shot rate, which could be a couple orders of magnitude lower than needed for a power plant. The target design would be determined in the single shot experiments. It will be possible to test several IFE chamber concepts since they can be tested at reduced scale and low power and thus we expect relatively inexpensively. ${ }^{3}$

Once a chamber is selected for further developments, construction of a Pilot Plant can begin. We propose that the decision to proceed with a Pilot Plant must be industry driven. While we expect industry involvement in defining power plant systems design and operating requirements throughout the $R \& D$ phase, it is unlikely that significant industry financial commitments will be made before high gain, high yield, low cost targets are demonstrated with a high rep-rate, efficient driver. The Pilot Plant would then provide a data base on system reliability which would be critical for decision to commercialize the technology. The Demonstration Power Plant that follows the Pilot Plant is likely to be a nearcommercial size plant with primary goal of demonstrating high reliability and economic viability.

\section{SUMMARY AND CONCLUSIONS}

plan:

In summary, the proposed IFE development

- Is divided into five major components - Target Physics, Drivers, Target Systems, Fusion Chambers, and Integrated Systems

- Is based on continued cooperation between DP and ER in all these areas with DP funding for some dualuse technologies critical to IFE

- Maintains direct- and indirect-drive target options until both have been tested on NIF

- Assumes the next driver beyond NIF will be a dualuse driver capable of meeting both defense and energy needs and that it can be upgraded and used for the Pilot Plant and possibly Demo phases
- Proposes that chamber testing and fusion power technology demonstrations in the ETF and Pilot. Plant be conducted at small size for high flexibility at low cost.

Conclusions for the near term (through 2005) based on the proposed plan include:

1) ICF Target Physics will continue to be the most important and costly component during the next 10 years. Successful demonstration of ignition is a key milestone for IFE.

2) Direct- and indirect-drive target options will be pursued by DP through testing on NIF. IFE R\&D should include driver, target systems, and fusion chamber technologies to implement either option.

3) IFE-relevant driver technologies require the majority of the ER funding to allow a dual-use, PNF driver decision once ignition is achieved.

4) Target Systems Technology development requires minimal effort until after demonstration of cryogenic targets for ICF. Low-cost, off-line tests can address key feasibility issues.

5) Fusion Chamber Technology funding will be limited in the near-term. Proof-of-principal tests of liquid wall chambers, improvement of predictive chamber analysis codes, and limited radiation damage testing are key elements.

6) In the near term, the Integrated Systems component of the plan will be limited to systems assessments.

\section{REFERENCES}

1. J.A. Paisner, E.M. Campbell, and W.J. Hogan, "The National Ignition Facility Project," Fusion Technol. 26, 755 (1994).

2. D.H. Crandall, "The Need for the National Ignition Facility'," Proc. ANS 12th Topical Mtg. on the Technology of Fusion Energy, Reno, NV, June 1620, 1996.

3. W.R. Meier and W.J. Hogan, "An Integrated Test Facility for Inertial Fusion Energy Using Heavy Ion Drivers," Proc. 15th IEEENAPSS Symposium on Fusion Engineering, Hyannis, MA, Oct. 11-15, 1993, p. 1001.

4. B.G. Logan, M.T. Tobin, W.R. Meier, "The Role of the National Ignition Facility in the Development of Inertial Fusion Energy," UCRL-ID-119383 (April 1995).

5. J.P. Knauer, "Recent Experimental Results from the Omega Laser Fusion Facility," These proceedings

6. J.D. Sethian et al., "The Nike KrF Laser Facility," Proc. AlVS 12th Topical Mtg. on the Technology of Fusion Energy, Reno, NV, June 16-20, 1996. 
7. R.O. Bangerter, "The Heavy Ion Program for Inertial Fusion Energy," Proc. ANS 12th Topical Mtg: on the Technology of Fusion Energy, Reno, NV, June 16-20, 1996.

8. C.D. Marshall et al., "Diode-Pumped, Gas-cooledslab Laser Performance," Proc. OAS Trends in Optics and Photonics on-Advanced Solid State Lasers, 1, 208 (1996) (San Francisco, CA, Jan. 31 - Feb. 2, 1996).

9. C.D. Marshal et al., "Diode-Pumped YtterbiumDoped $\mathrm{Sr}_{5}\left(\mathrm{PO}_{4}\right)_{3} \mathrm{~F}$ Laser Performance," IEEE J. of Quantum Electronics, 32, 4, 650 (1996).

10. R. Petzoldt and R.W. Moir, "Target Injection and Tracking for Inertial Fusion Energy," Proc. International Symp. on Heavy Ion Inertial Fusion, Princeton, NJ, Sept. 6-9, 1995, (Fusion Engineering and Design, in press, 1996).

11. M. Longeot, P. F. Peterson, "High Reynolds Number Stationary Sheet Jets for the HYLIFE-II Inertial Confinement Fusion Reactor, Proc. ANS 12th Topical Mtg. on the Technology of Fusion Energy, Reno, NV, June 16-20, 1996.

12. A. T. Anderson, A. K. Burnham, and M. T. Tobin, "Modeling and Experiments of X-ray Ablation of National Ignition Facility First Wall Materials," Proc. ANS 12th Topical Mtg. on the Technology of Fusion Energy, Reno, NV, June 16-20, 1996.

This work was performed under the auspices of the U.S. Department of Energy by Lawrence Livermore National Laboratory under contract \#W-7405-Eng-48. 
Technical Information Department • Lawrence Livermore National Laboratory University of California • Livermore, California 94551 